\title{
Physicians' Values and Their Career Stage
}

\author{
ROBERT T. Bi.ACKBURN \\ University of Michigan
}

AND

Thomas G. Fox

CMDNJ-Rutgers Medical School

\begin{abstract}
Professional values of 241 practicing physicians were determined from factor analyzing their responses to 25 questionnaire items dealing with an ideal medical school in their vicinity. The seven factors (values)-(1) Academic, (2) Professional Separatism, (3) Support, (4) Social Welfare, (5) Research/Specialization, (6) Status/ Prestige, and (7) Convenience-were examined for their relationship to background characteristics (e.g., training) and practice (e.g., specialty). Few differences were found. However, when values were analyzed by age and career stage, significant fluctuations were found. Levinson's adult development theory was able to account for a sizeable portion of the observed variations. Practical and theoretical consequences are discussed in connection with physician stress at critical career stages.
\end{abstract}

Data were collected on 241 doctors in the immediate area of New Brunswick, New Jersey, in the course of conducting an inquiry for the College of Medicine and Dentistry of New Jersey-Rutgers Medical School. The school was about to expand and problems were anticipated when a greatly enlarged health facility matures in the midst of 500 highly trained practicing physicians. Included in the data were the physicians' opinions on issues affecting their careers. In doing so the physicians expressed values they hold with regard to the practice of medicine. It is the analysis of physician values and their change over a career that constitute the core of this paper. The findings have an important relevance in light of the recent growing discussion with regard to adult development, work stress, and physicians' health.

\section{CONCEPTUAL FRAMEWORK}

Levinson, Darrow, Klein, Levinson, and McKee's (1978) conception of adult development stages was used to guide the analysis of value 
constancy and change physicians can be hypothesized to experience at successive ages. Levinson found stable and transition periods to occur chronologically in small samples of adult men in four different occupations. (Other adult theorists have similar periods of relative active and inactive development.) While the data here are cross-sectional rather than longitudinal, the homogeneity of the professional group should minimize cohort effects. One hypothesizes that physician concerns with their careers and their lives will change with time; that is, the degree to which they value different activities and arrangements will not remain constant.

This study recognizes the expanding research literature on stress visa-vis physicians which began some time ago. (See, e.g., Russek (1962) and Maddison (1974).) It does not, however, build directly on these studies. Rather, it introduces age-related findings which suggest some career stages are more stressful than others for practicing doctors.

\section{METHODS}

The survey instrument which provided the above demographic data was developed after interviews with nine physicians in the New Brunswick area and in Ann Arbor, Michigan, where pilot testing and revisions were conducted. Studies on professionals show that self-reported data are highly accurate (Allison \& Stewart, 1974; Blackburn, Pellino, Boberg, \& O'Connell, 1980). The survey instrument asked respondents to rate the relative importance of a number of characteristics of an ideal university medical school along a scale from "critical/essential" to "not really that important." The physician responses to these 25 statements are listed in the order in which the items appeared.

\section{Sample}

The population was selected from the roster of the Middlesex County Medical Society. This voluntary organization believed more than $90 \%$ of the area physicians were members and that all specialties were well represented. The society endorsed the study. Based on their prior surveys, staff predictions for the return rate ranged from 10 to $40 \%$. The 241 responses constitute $50 \%$ of the mailed instruments when conservative allowances are made for those returned for incorrect address, deceased, and other undeliverable questionnaires.

Responses from first and second mailings were tested for similarity on both age and medical specialty. While the second mailing produced slightly more respondents over age 70 (returns came from Florida - after forwarding, presumably from semiretired doctors), the differences by age category and physician practice were not statistically significant. (A separate analysis for another phase of the study tested response rates by ethnic/religious categories and also found no significant differences with the proportions of the "total" population.) While a $50 \%$ response is less than desired (it 
is what most surveys of academics achieve), the similarity of the respondents from two mailings and the accord with the respondents with the sample universe support the belief that the subjects analyzed in the study are representative of the area physicians.

\section{RESULTS}

\section{The Physician Population}

The typical Rutgers' arca physician is a 48-ycar-old marricd male, although the age range is appreciable (from 30 to 90 ). Over a third graduated from private research universities, the most academically selective in the country. (In terms of the college-going population as a whole, only $3 \%$ of the students are in these universities.) Furthermore, the majority of these doctors are indigenous to the greater New Jersey area. Those who have migrated to Middlesex County, in the main, have not come from very far away.

These doctors went uninterrupted through the school system-from high school to undergraduate school to medical school. The medical schools they attended similarly show a disproportionate selection from the private sector. However, their medical school's quality rating extends over a broader range than was the case for their undergraduate education, an almost inevitable fact given the increased level of competition for entry (Cole \& Lipton, 1977). Even then, the single largest group graduated from a most prestigious medical school. Few have had other formal schooling leading to degrees other than the MD, 12 having earned a mastcr's degree and one a PhD.

Another indication of the local nature of the population can be seen from where these physicians served their internships and residencies. Setting aside those who trained abroad, only $22 \%$ had this part of their training outside of the Philadelphia, New York, and New Jersey area. (The number for New Jersey is remarkably high when it is recognized that there was no medical school in the state prior to 1956.) Only $10 \%$ of these doctors are engaged in primary care, a proportion far different from what is thought desirable. The percentage of doctors with Boards is high (75\%). Middlesex County is populated with well-trained specialists. In summary, the data reveal an able, highly educated, and privileged group of physicians, persons who have had a large number of common experiences over an extended period of time.

\section{Physician Values (The Factors)}

The responses to the 25 items were subjected to orthogonal varimax rotations until the eigenvalues became less than 1 . This yielded a sevenfactor solution. It is displayed as part of Table 1, with the factor loadings alongside of each of the items and the item mean and standard deviation in the columns before the items. Those items which are used in each 


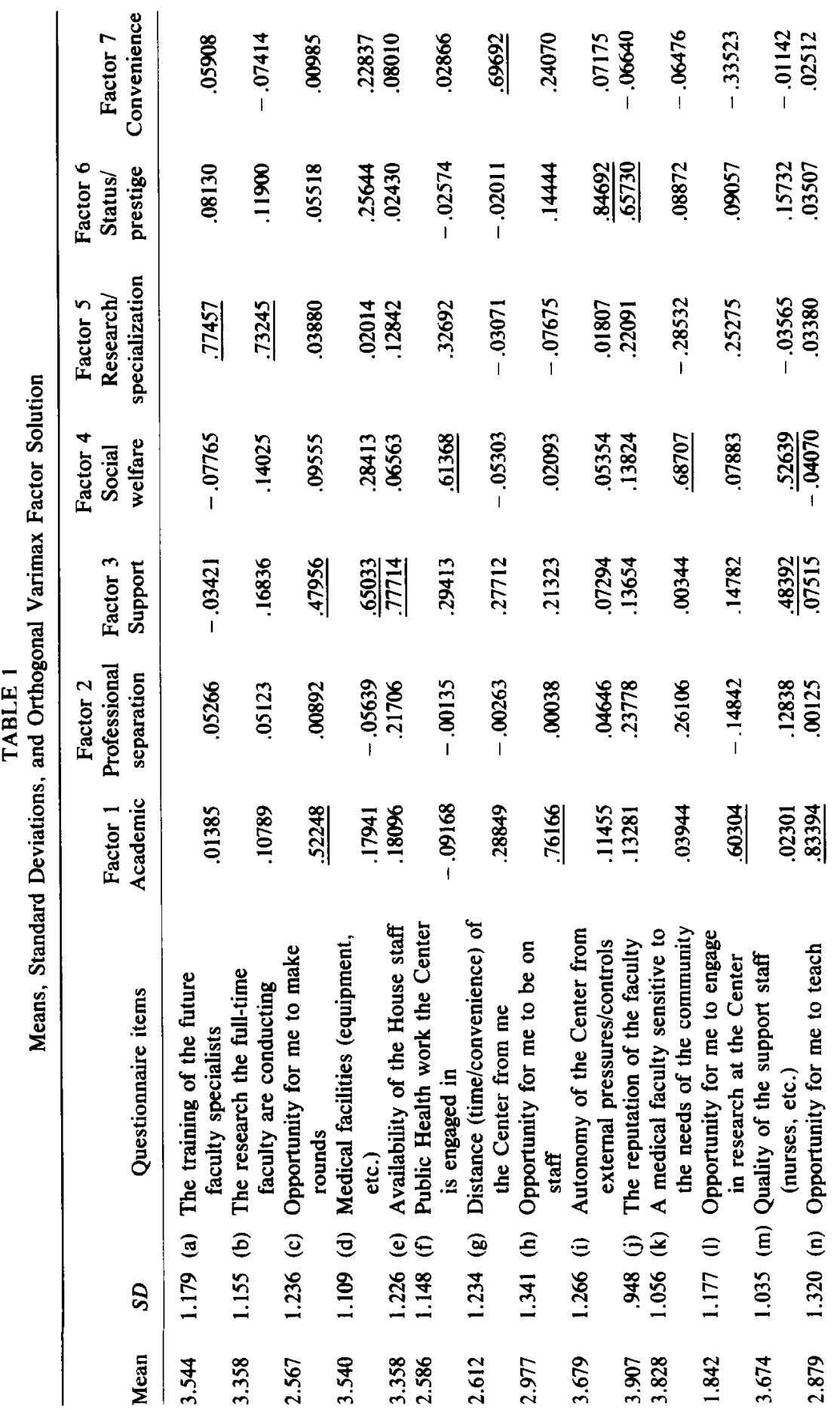




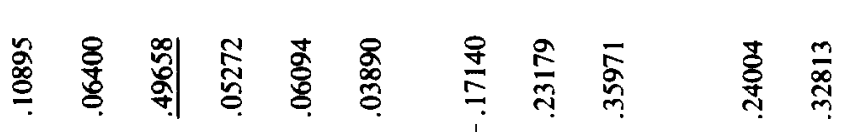

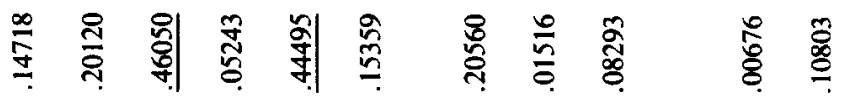

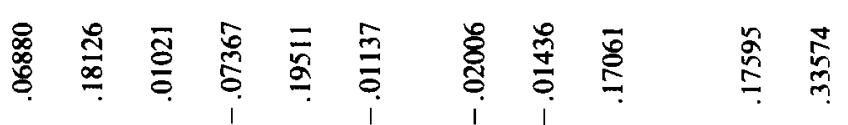

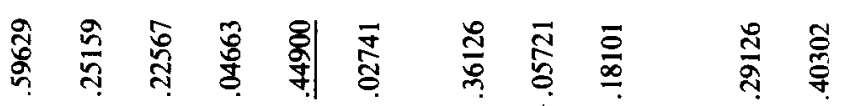

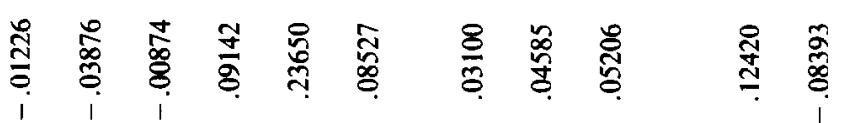

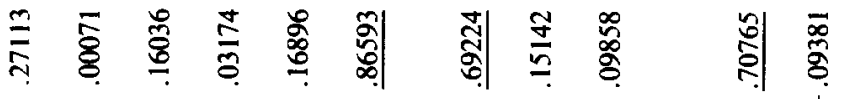

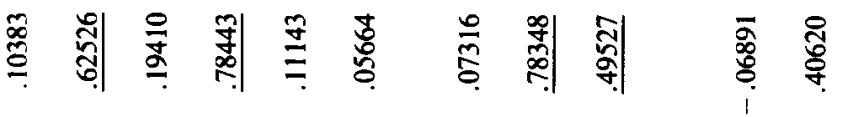

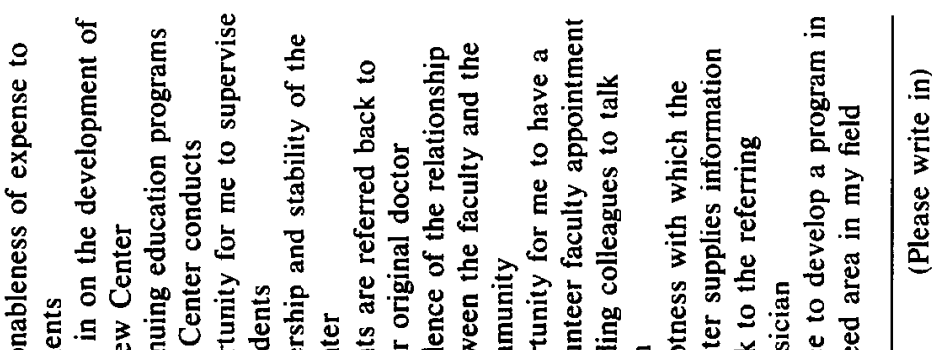

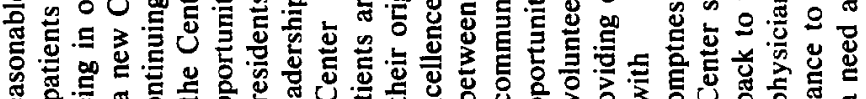

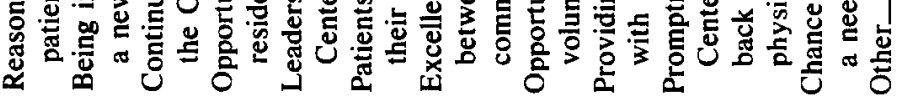

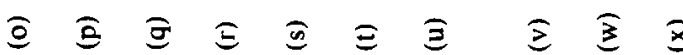

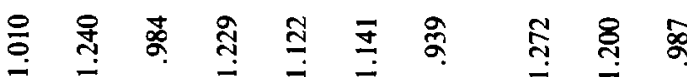

$\sqrt{3}$

ત્ণ

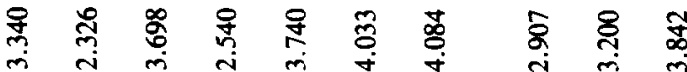

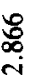

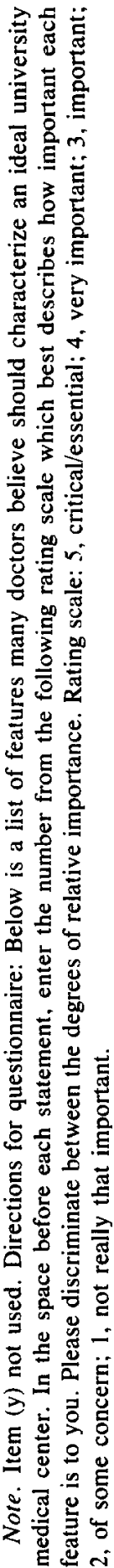


factor have their loading underscored. A cut-off point of .45 was used to retain an item in a factor. The number of items per factor range from eight in Factor 1 to two in Factors 5 and 7. Twenty-four of the 25 items contributed to the factor analysis. Four items loaded on more than one factor but none on more than two factors. The factors are psychologically meaningful and are relatively unambiguous. The factors have typical reliability coefficients. (Cronbach $\alpha$ 's are in parentheses in Table 2.)

The mean item scores show that those receiving the highest score were (u) "excellence of the relationship between the faculty and the community," (t) "patients are referred back to their original doctor," (j), "the reputation of the faculty," (x) "promptness with which the Center supplies information back to the referring physician," and (k) "a medical faculty sensitive to the needs of the community." All of these had scores of 3.8 or higher, a rating of "very important."

On the other end of the scale were items (p) "being in on the development of a new center," (d) "medical facilities," (r) "opportunity for me to supervise residents," and (f) "public health work the Center is engaged in," all of which had scores of 2.6 or less, scores in between having "some concern" and being "important." For the most part, the items just enumerated at both the high and low ends also had a low standard deviation. That is, there was a comparatively high degree of agreement among the respondents as to the relative importance of these items. The greatest variations $(\sigma)$ occurred on items (n) "opportunity for me to teach" and (h) "opportunity for me to be on staff."

Factor 1 is labeled "Academic" and is loaded with items that suggest an opportunity to be directly engaged with the university. This factor has the largest number of items. However, it also has the lowest mean score, namely, 2.655 out of a possible score of 5 . This factor has the highest reliability $(\alpha=.85)$.

Factor 2 is called "Professional Separatism." It deals with patients being referred back to the original doctor, the prompt supply of information from the referring physician, and maintaining an excellent relationship between the faculty and the community. It has the highest mean, 3.986.

Factor 3 has been called "Support." The four statements which comprise it characterize how a first-rate medical facility would aid the practicing physician.

Factor 4, "Social Welfare," has items dealing with public health and a medical faculty sensitive to the needs of the community.

Factor 5, "Research/Specialization," deals with the training of future specialists and the research the medical school faculty is conducting.

Factor 6, "Status/Prestige," deals with matters of the school's reputation and freedom from external controls.

Factor 7 has been called "Convenience." The two items comprising it have to do with distance to the center and its provision of continuing medical education. 
The intercorrelations of the factors are found in Table 2 along with the means and reliability coefficients. It can be seen that the factors are interrelated despite their distinctiveness. All intercorrelations are positive, in the low to moderate range. The four highest intercorrelations result in part from the fact that those factors each have a common item (Factors 1 and 3 with $r=.53$; Factors 3 and 4 with $r=.55$; Factors 4 and 6 with $r=.61$; and Factors 6 and 7 with $r=.50$-see Table 1). The positive intercorrelations also suggest that there exists a general factor which pervades the profession.

In addition, the intercorrelated factors are distinct despite some having common items. For example, Factors 4 (Social Welfare) and 6 (Status/ Prestige) have "leadership and stability of the Center" as a common item, a concern for both even though in one instance the relationship is to the community (Factor 4) and in the other it is to the organization (Factor 6). Furthermore, the changes in factor salience are random. (See Fig. 1 and the presentation below.) (When three and four-factor solutions were examined for the internal consistency of the items, problems arose. Professional, academic, welfare, and status items were intermixed and conceptual distinctiveness was lost. Hence, the larger factor solution was accepted and, as stated above, it met statistical criteria.)

\section{The Factors and the Physicians}

With respect to the career preparation of the physicians, there is little relationship between the values they hold and where they did their undergraduate work, received their MD, or did their internship and residency.

TABLE 2

Factor Intercorrelations: (Factor Means in First Parentheses, ${ }^{*}$ Cronback $\alpha$ 's in the Second)*

\begin{tabular}{|c|c|c|c|c|c|c|c|}
\hline \multicolumn{7}{|c|}{ Factors } & \\
\hline $\mathbf{1}$ & 2 & 3 & 4 & 5 & 6 & 7 & \\
\hline \multirow[t]{7}{*}{ - } & .11 & .53 & .21 & .16 & .37 & .44 & F-1: Academic (2.655) $(\alpha=.85)$ \\
\hline & - & .29 & .50 & .12 & .42 & .20 & $\begin{array}{c}\text { F-2: Professional Separatism } \\
(3.986)(\alpha=.75)\end{array}$ \\
\hline & & - & .55 & .18 & .45 & .38 & F-3: Support (3.285) $(\alpha=.66)$ \\
\hline & & & - & .20 & .61 & .27 & $\begin{array}{l}\text { F-4: Social Welfare (3.433) } \\
\qquad(\alpha=.70)\end{array}$ \\
\hline & & & & - & .27 & .11 & $\begin{array}{c}\text { F-5: Research/Specialization } \\
(3.451)(* *)\end{array}$ \\
\hline & & & & & - & .50 & $\begin{array}{l}\text { F-6: Status/Prestige (3.756) } \\
\qquad(\alpha=.69)\end{array}$ \\
\hline & & & & & & - & F-7: Convenience $(3.166)\left({ }^{* *}\right)$ \\
\hline
\end{tabular}

Note. *Rating scale: 5 , critical/essential; 4 , very important; 3 , important; 2 , of some concern; 1 , not really that important.

(**) Reliability cannot be calculated for two item scales. 
The one exception is those doctors whose education and training were done abroad. On the average, this group scored lower on academic interests (Factor 1) and higher on professional separatism (Factor 2) than did the physicians who were educated and prepared for their career in the United States. In general, though, physicians in the study carry a set of values which are not directly related to either their schooling or their internship and residency experience.

When one looks at the values that the physicians hold in relationship to their medical specialties and subspecialties, again there are more similarities than differences. For the most part, values are distributed throughout the profession and not localized in specialties. Surgeons are an exception. They score higher on all of the factors, with the exception of Factor 5 (Research/Specialization), where they are near the mean. The inference to be drawn at this point is that within each of the various medical specialization groups, there is a good mix of values-from concerns for an academic career, to status and prestige, to regard for social welfare.

Also, the physician values are not generally related to future career plans or to problems that they foresee with respect to the development of the Medical Center (other parts of the questionnaire). Recall that these are practicing physicians from similar backgrounds and schooling who have been socialized through highly common experiences over an extended period of time. They interact through a network of social as well as professional relationships. It is not surprising that differences across specialties are minimal.

\section{Value Stability, Chronological Age, and Career Stage}

Age is always a confounding variable when studying people's beliefs and their behavior. Physicians are no exception.

Figure 1 displays the seven values across a scale of chronological age. (The ages are midpoints of the grouped data; e.g., age 32 is the midpoint of the 30-34 age category.) The great number of variations, that is, the rises and falls of importance of the values, is apparent. The question becomes one of whether or not anything more than random fluctuations is involved. The reliability coefficients suggest otherwise. Furthermore, when subjected to one-way analysis of variance, between three and five of the means for the eight age groups fall outside the $95 \%$ confidence levels for the total population mean on every one of the seven factors. That is, there are significant differences between age groups on the factors. In addition, $F$ values for three of the factors are statistically significant across age groups. That is, age groups differ in the importance they give to the different values. The interest here, however, is in the patterns of change, not in the amount nor in the values themselves. What analysis of variance demonstrates is that the fluctuations are statistically unlikely to be chance occurrences. 


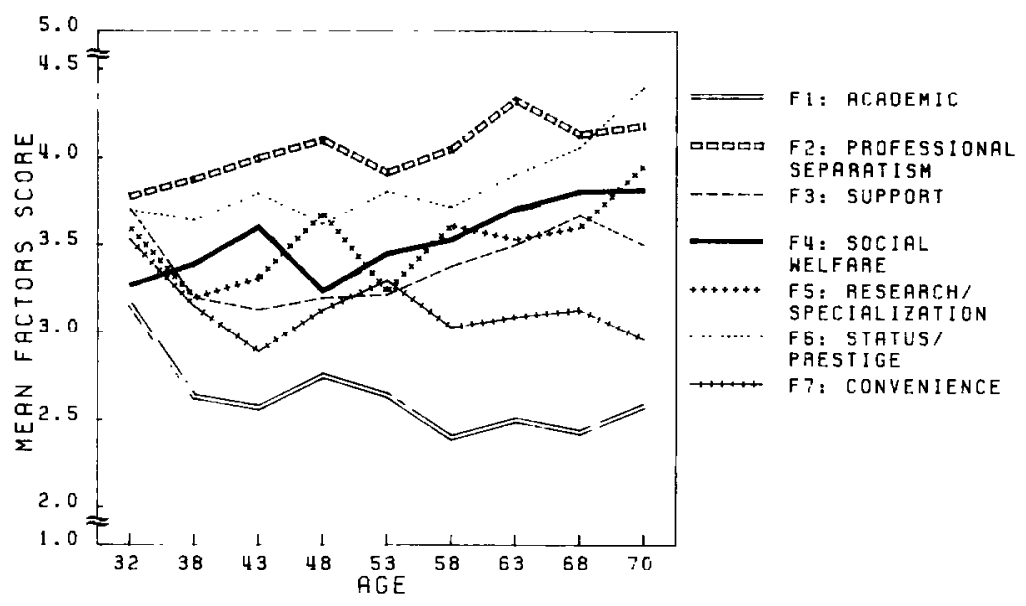

FIG 1. Mean factor scores by 5-year age groups.

Introducing adult development theory brings some order to the data. (1) The development model of Levinson et al. has been employed, although other developmental theories, for example, Hall and Nougaim (1978), Sheehy (1976), Gould (1978), or Super (1980), might have been used. (For the most part, however, the others have focused on the early ages (before 30) and offer comparatively little evidence for middle and advanced years. Even Levinson's work does not extend systematically to late adulthood, but his is the most advanced.)

Adult development theory suggests there will be periods of differing degrees of stability. Nine different indicators of stability can be calculated from the data and set against the theory. One indicator is the extent of variation members of an age cohort have with respect to the values, a larger variation being expected during transition periods than within more stable developmental periods. To determine the degree of variation, the standard deviations for the means for each factor for each of the nine age groups were rank ordered from 1 (high) to 9 (low). The mean of the ranks is 4.8 .

As can be seen in Column A, Table 3, at age 32 the rank average for the standard deviations of the seven factors is close to that average (4.8). Variation then becomes greater. The average rank increases to 3.8, that is, comes closer to 1 (maximum possible variation) than to 9 (the number of age intervals used). The degree of variation remains higher than average through age 43 . It then changes to less variation (ranks above 4.8) by age 48 and continues through age 53, the "midlife stability" stage. At the "age 50 transition" stage and at the "late adult transition" stage, the ranks are 4.3 and 3.6, respectively, again indicating more variation 
BLACKBURN AND FOX

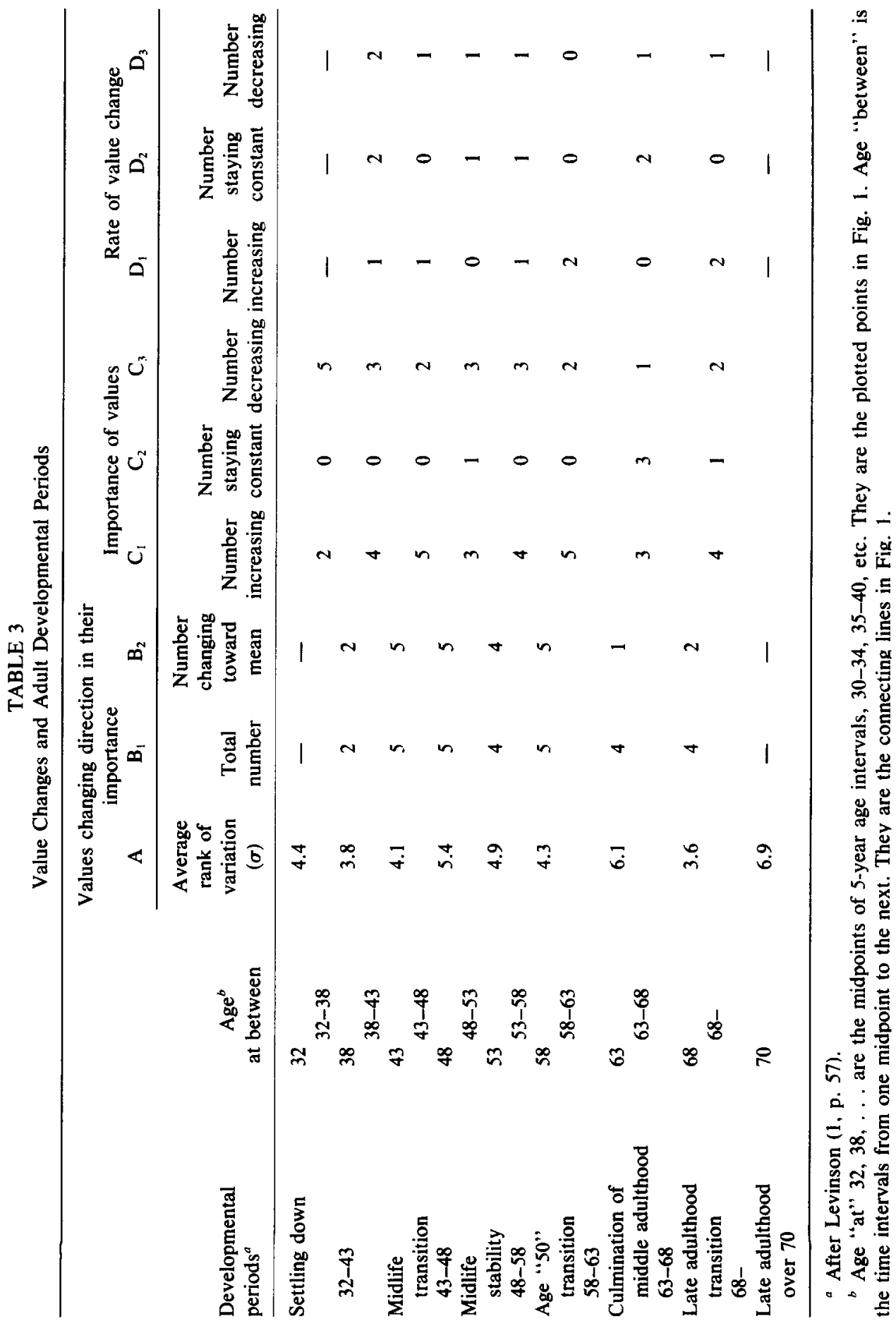


and less stability. There is much less variation at the culmination of midlife stage and in late adulthood stage (the two lowest ranks, 6.1 and 6.9 , respectively), as the theory predicts. The variation in the importance of different values fluctuates with developmental age in accord with theory.

A second indicator of developmental stability is the number of reversals of value salience an individual demonstrates, that is, the frequency with which values were increasing in salience begin to decrease, and vice versa. From Fig. 1 one can count the slope reversals for age cohorts over the seven factors. The results are shown in column $B_{1}$ in Table 3 , the entries indicating the number of times that a value changes from one of decreasing to one of increasing importance, and vice versa. As can be seen, the number of changes are maximum (5) at the midlife transition stage (ages 43 and 48), and again at the age " 50 " transition stage (age 58 in the Table). The number of shifts in direction are less in the settling down periods (only two changes in direction at age 38, for example). They are somewhat less (four each) in the stages of midlife stability, and the culmination of middle adulthood stages. The four reversals in the "late adulthood transition" stage are not in accord with the other entries.

A third and related indicator of developmental stability is the number of times value reversals are toward (rather than away from) the population mean ( $B_{2}$ in Table 3$)$. At midlife time, the reversals would be predicted to be toward the mean, not away from it. There are ten reversals in the importance of the seven values during midlife transition. They show that when the changes took place in value importance, physicians overreacted. They went past the mean and then shifted back. That is, at this transition stage there are double fluctuations. Shifts in the importance of different values also occur during the more stable periods of the life cycle, but they are not "flip-flopping" to the same degree. Again the "late adulthood transition" stage has a frequency (2) more associated with stability than change.

A fourth set of indicators can be constructed from counting the number of values during each developmental period that are either increasing (Column $\left.C_{1}\right)$, remaining constant $\left(C_{2}\right)$, or decreasing in importance $\left(C_{3}\right)$. Here one looks at the lines in Fig. 1 between the age category midpoints. For example, between 32 and 38 only two of the factors-Factors 1 and 4 -are rising. As is shown in column $C_{1}$, the most frequent periods for the increasing importance of values are during the three transition periods $(5,5$, and 4 , respectively). Their salience declines or remains constant during the more stable periods, that is, during "settling down" (5 and 3 decreasing - Column $\mathrm{C}_{3}$ ), "midlife stability" ( 3 and 3 decreasing), and through the "culmination of middle adulthood" stages ( 3 not changing at all-Column $\mathrm{C}_{2}$ ).

Still another way of analyzing values and developmental periods is to 
examine the extent to which current value changes are intensifying (Column $\left.D_{1}\right)$, moderating $\left(D_{3}\right)$, or remaining constant $\left(D_{2}\right)$ at each developmental period. By noting whether the change slope during a time interval is increasing (positively or negatively), decreasing, or remaining the same (rate unchanged), inferences can be made. By way of illustration, between 38 and 43, the slope of Factor 1 is less steep than it was between 32 and 38; that is, while still decreasing, it is moderating and appears as an entry in Column $D_{3}$ for the $38-43$ age group. What is shown in Table 3 , then, is that the importance of none of the seven values is remaining constant during the "midlife transition," "age 50 transition," and "late adulthood transition" stages (zeroes in Column $\mathrm{D}_{2}$ ).

In summary, the apparent lack of order of Fig. 1 can be given meaning when examined from an adult developmental theory perspective. The fit is not perfect, however, as the data reveal and as one might have anticipated. The overall congruences from a number of approaches are what give support to the conclusion. The discussion below takes up discrepancies and methodological issues.

\section{DISCUSSION}

First of all, there is a general pattern. (See Fig. 1.) The physician begins his career with mostly higher than average value salience. Then the importance of many values declines. Those who are most concerned with academic matters, research/specialization, support, and convenience are the youngest group of physicians. At this initial point of their career, the doctors seem less concerned with status and prestige. But status/ prestige and professional separatism tend to increase rather steadily with age, those in the older three age groups being the highest on both of these factors.

Some of the findings are in accord with expectations. Those who are less interested in academic medicine-which tends to plot inversely with professional separatism and status - are the physicians who have developed and maintained a practice over an extended period of time. There is, however, a tendency for the initial enthusiasm of the young physicians to wane, rise again in the $46-50$ age span, drop off rather precipitously after that, fluctuate somewhat for a number of years, and then rise again as retirement age approaches. Said another way, there is an early eagerness in the physician that is also related to academic medicine (although the interest is appreciably greater in teaching than it is in research). His altruism has not been squelched by the medical school, as some claim; rather, his early academic enthusiasms fall off when these goals and values are not satisfied, when the business of establishing oneself and looking after one's financial security takes over. (Note the rise of Factor 2.)

However, the midlife transition stage affects how and what he values. Perhaps there is dissatisfaction and/or frustration with the routine of 
daily practice and hence a new interest in academic medicine occurs. Perhaps an academic career is perceived to be a life-style with, if not reduced, then more regular hours. There is a career peak here. There are few visible symbols of success (e.g., a promotion) other than increased income, a reward not really needed. This is a stressful period. The individual physician may have great difficulty in satisfying mixed desires. Consequently, his interest in academic medicine declines to new lows, only to rise slightly once more in later life. In these later years, academic activities are more related to status and prestige than they were at the outset of the career.

The data, of course, have limitations, both substantive and methodological. As for the methodological, the data are cross-sectional, not longitudinal, and this raises some concerns as to whether or not successive age cohorts are alike on the critical variables that affect results. (See e.g., Wohlwill (1973).) A good case can be made for cross-sectional analyses in this instance because of the high uniformity in background of these subjects for all age groups. As was shown in the description of the population, here are a number of young men who had very similar socializing experiences. They had a continuous schooling, one which included high sequestration. The socialization of values, the common experience of medical school through residency, and the establishing of a practice would be much more alike for people in this occupation than for almost any other that can be thought of, the exception perhaps being clergy in selected denominations.

This substantive discrepancy between the data and Levinson is that there is a time lag of about 5 years that runs almost throughout. (The sequence, however, is in almost perfect accord with theory.) Levinson argues from his study of $\mathbf{4 0}$ men in four different occupations that what is involved is chronological, not career stage. However, with this population of physicians a case can be made otherwise.

For example, the early stages of the Levinson et al. model of entering the adult world and age 30 transition stage are not really the same for physicians as they are for people going into the typical world of work, or even into a host of other professions. Once the young person enters medical school at age 22 , the route is well fixed. There are 4 years of sequestered schooling followed by a steady diet of work in the hospital. A physician is already in the adult world as a resident even if the established practitioner treats him like an apprentice. He can even stay on for additional years trying a hand at academic life and simultaneously developing a specialty.

There really is not an occasion for a doctor to be involved in the typical transitions that Levinson describes. Doctors are not trying out different jobs or places. Furthermore, the physician is beginning an independent professional career at a later age (30-34) than are persons in 
most other occupations. (The academic profession would be an exception.) The settling down stage is the establishment of a practice. All of these factors act to delay the midlife transition stage.

Also, the other end of the life cycle will be different for physicians from what Levinson and others describe. Unlike most theorists, who claim a sharp break at age 65 , the physician is not retiring then. In fact, many never do and are practicing at various degrees of intensity throughout their lives. Many in this study population were above 70. The "trauma" of retirement would not be the same for physicians. Our data corroborate this interpretation. Late adulthood is indeed after 70 , not after 60 . In all, then, moving the scale more in line with career age and delaying slightly the chronological age events are legitimate expectations for this population of adults.

With these methodological assumptions and substantive alterations of Levinson accepted, adult development theory receives corroboration. In addition, the data contribute some knowledge about late adult development, an area not studied nearly as extensively as the midlife stages.

Last, it does look as if midcareer times are difficult ones for many practicing physicians. Their values are switching rapidly. Two kinds of concerns enter here. From a practical standpoint there appears to be a genuine need for counseling for many physicians at this career stage. The signs of stress-for example, alcohol and marital interruption-and a search for stability are suggested by the see-sawing of value salience. From a theoretical perspective, an important area for research has been identified.

Continuing medical education might enter on both accounts. It could take on the role of dealing with personal and career problems physicians face in addition to the services it already provides with respect to updating skills, transmitting knowledge, and related professional practice activities. Continuing medical education could also contribute to adult development theory by conducting much needed systematic, longitudinal studies on physicians' careers.

\section{REFERENCES}

Allison, P. D., \& Stewart, J. A. Productivity differences among scientists: Evidence for accumulative advantage. American Sociological Review, 1974, 39, 596-606.

Blackburn, R. T., Pellino, G., Boberg, A., O'Connell, C. Faculty development programs, the improvement of instruction, and faculty goals: An evaluation. In R. Edgerton (Ed.), Current issues in higher education. Washington D.C.: American Assoc. for Higher Education, 1980. Pp. 32-48.

Cole, J., \& Lipton, J. The reputations of American medical schools. Social Forces, 1977. $55,662-684$.

Gould, R. L. Transformations. New York: Simon \& Schuster, 1978.

Hall, D. T., \& Nougaim, K. An examination of Maslow's need hierarchy in an organizational setting. Organizational Behavior and Human Performance, 1968, 3, 12-35. 
Levinson, D. J., Darrow, C. N., Klein, E. B., Levinson, M. H., \& McKee, B. The seasons of a man's life. New York: Knopf, 1978.

Maddison, D. Stress on the doctor and his family. Medical Journal of Australia, 1974, 2 , 315-318.

Russek, H. I. Emotional stress and coronary heart disease in American physicians, dentists, and lawyers. American Journal of Medical Science, 1962, 243, 716-725.

Sheehy, G. M. Passages: Predictable crises of adult life. New York: Dutton, 1976.

Super, D. E., A life-span, life-space approach to career development. Journal of Vocational Behavior, 1980, 16, 282-298.

Wohlwill, J. F. The study of behavioral development. New York: Academic Press, 1973.

Received: November 30, 1981. 